\title{
Die Bedeutung einiger anorganischer Komponenten des Seewassers für die Turgorregulation von Chaetomorpha linum (Cladophorales)
}

\author{
Hanswerner Kesseler \\ Biologische Anstalt Helgoland, Meeresstation, Helgoland
}

\begin{abstract}
The importance of some inorganic components of sea water for the turgorregulation of Cbaetomorpba linum (Chladophorales). Some algae of the intertidal zone are capable of regulating their turgor pressure. In 1896 Drevs had already shown that this process is affected primarily by accumulation (positive turgor-regulation) or extrusion (negative turgor-regulation) of mineral salts and that transformation of stock material (e. g. starch) into osmotic active substances (e. g. sucrose) and vice versa plays no important role. His results are being confirmed by the present paper. In Chaetomorpha linum (Müller) Kürzing, lowering of salinity resulted in a significant release of potassium and chlorine (negative turgor-regulation). Changes in sodium content were only small. In algae exposed to a salinity of $30 \%$, the total sodium concentration was only about $10 \%$ that of the external medium. Salinity increase led to a marked accumulation (positive turgor-regulation) of potassium and chlorine. Even in this process sodium was engaged only to a small degree - despite its high concentration in the surrounding medium. In both cases internal changes in sodium content amounted only to about $5 \%$ of the total osmotic changes in the external medium. After transfer from $30 \%$ salinity into isosmotic artificial sea water without $\mathrm{Ca}^{*}$, a rapid loss of potassium and chlorine was observed. The abrupt decrease of the calcium content accompanied by a marked swelling of cell walls, leading to a significant reduction of cell space, is interpreted as ion exchange process changing the cell wall $\mathrm{Ca}$ " against $\mathrm{Na}$.
\end{abstract}

\section{EINLEITUNG}

Die meisten biochemischen Reaktionen, welche für einen Organismus lebenswichtig sind, finden in vitro nur unter Einhaltung ganz bestimmter physikochemischer Bedingungen statt. Der Organismus als Ganzes vermag hingegen im allgemeinen noch unter Umweltverhältnissen zu existieren, die von diesen hochspezifischen In-vitroBedingungen nicht unbeträchtlich abweichen.

Diese erstaunliche Fähigkeit, die schon bei den „einfachsten“ Protophyten und Protozoen mehr oder weniger deutlich ausgeprägt ist, beruht auf der regulativen Organisation aller Lebewesen. Sie ermöglicht es ihnen, je nach den ökologischen Erfordernissen ihrer Umwelt sich den verschiedensten, für den Ablauf der biochemischen Grundprozesse störenden Milieueinflüssen bis zu einem gewissen Grade zu entziehen und an den Reaktionsorten jene Bedingungen aufrechtzuerhalten, unter denen allein 
die lebenswichtigen Reaktionen möglich sind. Regulationsvorgänge gehören also zu den allgemeinsten und wichtigsten Lebensäußerungen.

Für Meeresalgen von Standorten mit stark wechselndem Salzgehalt spielt besonders die Regulation des Zellturgors eine bedeutsame Rolle. Wie diese bei der Grünalge Chaetomorpha linum (Müller) KüTzING vonstatten geht, und welche Bedeutung dabei einigen anorganischen Komponenten des Seewassers zukommt, soll durch die folgende Arbeit gezeigt werden.

\section{ALLGEMEINES}

Definitionsgemäß ist der Turgor $\left(\mathrm{p}_{\mathrm{T}}\right)$, d. i. der reelle hydrostatische Druck innerhalb einer Pflanzenzelle, im osmotischen Gleichgewicht gleich der Differenz zwischen den osmotischen Potentialen von Innen- $\left(\pi_{i}\right)$ und Außenmedium $\left(\pi_{\mathrm{e}}\right)$. Diese Gleichgewichtsbedingung läßt sich also in die Formel kleiden:

$$
\mathrm{p}_{\mathrm{T}}=\pi_{\mathrm{i}}-\pi_{\mathrm{e}}
$$

Aus dieser Gleichung ergibt sich, daß jede Erhöhung der osmotischen Konzentration des Außenmediums eine Herabsetzung des Turgors zur Folge haben muß und umgekehrt - vorausgesetzt, daß das osmotische Potential des Innenmediums dabei keine Veränderung erfährt.

Für Meeresalgen, die an Standorten mit stark wechselndem Salzgehalt leben, insbesondere also für Formen der Gezeitenzone, würde dies bedeuten, daß sie bei Erhöhung des Salzgehaltes - etwa beim Eindunsten kleiner Wasseransammlungen auf dem Watt zur Ebbezeit - ständig der Gefahr der Plasmolyse ausgesetzt wären. Andererseits würde eine übernormale Erhöhung des Turgors nach plötzlicher Aussüßung, etwa durch Regengüsse, für die Litoralalgen die nicht minder große Gefahr des Platzens heraufbeschwören. Höfler (1931), Biebl (1937) und Collander (1939) konnten diesen Vorgang unter natürlichen Bedingungen an einigen großzelligen Algen studieren.

Manche Formen von besonders exponierten Standorten, darunter auch Chaetomorpha linum, sind nun in der Lage, diesen Gefahren durch Regulation ihres Turgors zu begegnen. Sie können bei Änderungen des Salzgehaltes im Außenmedium auch das osmotische Potential ihres Zellsaftes im gleichen Sinn und Ausmaß verändern. Der Zellturgor als Differenz dieser beiden Größen bleibt auf diese Weise stets annähernd konstant bzw. erreicht nach Ablauf der Regulationsvorgänge etwa wieder seinen Ausgangswert. In $\mathrm{Abb} .1$ sind diese Vorgänge - ausgehend von dem Normalzustand (A) - für die positive Turgorregulation (B) (= Erhöhung des osmotischen Potentials des Zellsaftes nach Anstieg des Salzgehaltes im Außenmedium) und für den entgegengesetzten Fall der negativen Turgorregulation (C) schematisch dargestellt.

Drevs (1896), der sich als erster eingehender mit der Frage nach dem Mechanismus der Turgorregulation befaßte, konnte u. a. auch an Chaetomorpha linum feststellen, daß bei diesem Vorgang die Umwandlung von Speicherprodukten in osmotisch aktive Substanzen - etwa von Stärke in Zucker - und umgekehrt keine Rolle spielt. 
Durch Veraschung von Materialproben aus Medien verschiedenen Salzgehaltes und gravimetrische Bestimmung des mineralischen Rückstandes kam er vielmehr zu dem Schluß, daß den Salzen des Seewassers bei der Regulation des Turgors eine entscheidende Bedeutung zukommen müsse.

$\mathrm{Zu}$ dem gleichen Ergebnis kam BuchHeIm (1915), der an der verwandten Art Chaetomorpha aerea fand, daß bei Algenfäden, die in hypertonische Seewasserlösungen mit verschiedenem Rohrzuckergehalt übertragen worden waren, ein Rückgang der Plasmolyse nur in den Versuchsansätzen mit Seewasserzusatz zu beobachten war. In reinen Rohrzuckerlösungen blieben die Zellen plasmolysiert.

Durch eigene Beobachtungen (KEsseler 1960, p. 122) konnte schließlich festgestellt werden, daß Zellen von Chaetomorpha linum auch ohne osmotische Belastung im Laufe der Zeit ihren Turgor verloren, wenn sie in eine salzfreie, seewasserisotonische Rohrzuckerlösung übertragen wurden. Nach Rückführung in normales Seewasser wurden sie dagegen rasch wieder turgeszent. Diese Beobachtungen zeigen, daß die Salze des Außenmediums - zumindest jedenfalls einige von ihnen - für das Funktionieren des Turgorregulationsmechanismus unentbehrlich sind. Die positive Turgorregulation, bei der das osmotische Potential des Zellsaftes eine Steigerung erfährt, muß

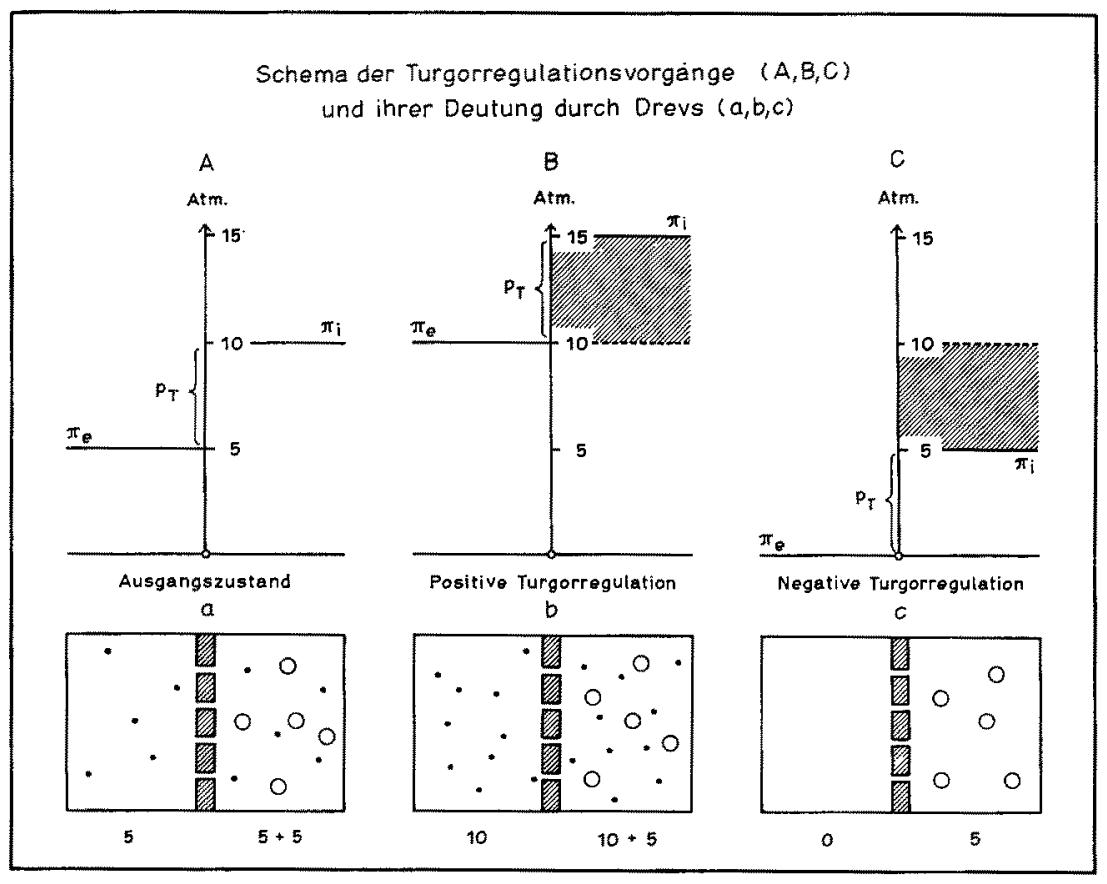

Abb. 1 A, B, C: Schema der Turgorregulationsvorgänge; $a, b, c$ : Darstellung ihrer Deutung durch Drevs (1896). Erläuterungen zu A, B, C: pT $\Rightarrow$ Zellturgor; $\pi_{\mathrm{e}}=$ osmotisches Potential des AuRenmediums; $\pi_{\mathrm{i}}=$ osmotisches Potential des Innenmediums. Schraffierung: Anteil, um den das osmotische Potential des Innenmediums nad Steigerung (Senkung) des Salzgehaltes im Außenmedium während der Turgorregulation erhöht (erniedrigt) wurde. Erläuterungen zu $a, b$, c: Punkte: Salze des Außenmediums; Kreise: Den Turgor bedingende, indiffusible biogene Substanz des Innenmediums; Schraffierung: Protoplasmamembran 
demnach vorwiegend durch Aufnahme von Salzen aus dem Außenmedium bewerkstelligt werden. Bei der negativen Turgorregulation müssen diese dann wieder abgegeben werden.

Uber die Möglichkeiten einer Turgorregulation durch Salzaufnahme bzw. -abgabe hatte schon DREvs (1896) Vorstellungen entwickelt, die diesen Vorgang in recht einfacher Weise zu beschreiben vermochten. Er nahm an (Abb. 1 a, b, c), die Salze des Außenmediums (in Abb. 1 durch schwarze Punkte symbolisiert), für die das Protoplasma vollkommen durchlässig sein sollte, seien innerhalb wie außerhalb der Zelle stets in gleicher Konzentration und in gleichem Verhältnis zueinander vorhanden. Außer diesen Salzen sei im Zellsaft aber noch eine ganz bestimmte Menge einer relativ großmolekularen biogenen Substanz - etwa Zucker - (in Abb. 1 durch offene Kreise dargestellt) gelöst, für die der Protoplast impermeabel sein sollte. Diese Substanzmenge sollte für den Unterschied zwischen den osmotischen Potentialen von Innenund Außenmedium und damit auch für die Konstanz des Turgors verantwortlich sein.

Diese Gedankengänge waren recht einleuchtend. Die Modellvorstellung vom Ablauf der Turgorregulationsvorgänge, die ihnen zugrunde lag, erwies sich jedoch später als zu einfach. Chemische Zellsaftanalysen anderer Autoren (Literatur bei STEINER \& EsCHRICH 1958 , p. 340) an einigen großzelligen Meeresalgen sowie eigene mikrokryoskopische Untersuchungen an Chaetomorpba linum (KESSELER 1959) zeigten nämlich, daß nicht alle Salze des Außenmediums gemäß ihrem Konzentrationsverhältnis im Seewasser an der Regulation des Turgors beteiligt sein konnten. Auf Grund dieser Beobachtungsergebnisse mußte vielmehr dem Kalium und dem Kalzium eine besondere Rolle für diesen Vorgang zugebilligt werden. Fehlte nämlich eines dieser beiden Ionen in dem für diese Untersuchungen benutzten künstlichen Seewasser, so unterblieb die Regulation des Turgors bzw. es kam zu schweren Störungen, die schließlich zum Zusammenbruch des osmotischen Systems führten.

Qualitativ war damit die Unentbehrlichkeit des Kaliums und des Kalziums für den Vorgang der Turgorregulation nachgewiesen worden. Uber ihre quantitative Beteiligung sollen die nun mitzuteilenden Befunde Auskunt geben.

\section{METHODIK}

Aus methodischen Gründen wurde zunächst die negative Turgorregulation, d. h. also die Erniedrigung des osmotischen Potentials des Zellsaftes nach Obertragung des Versuchsmaterials in ein Medium geringeren Salzgehaltes, untersucht. Dazu wurde im allgemeinen folgendermaßen verfahren: Materialproben von je $5 \mathrm{~g}$ Frischgewicht aus Seewasser von $30 \%$ Salzgehalt wurden in runde Schliffdeckelglasdosen $(\varnothing 8 \mathrm{~cm}$, Höhe $5 \mathrm{~cm}$ ) mit je $100 \mathrm{ml}$ Seewasser von $3 \%$ (bei den ersten Versuchen auch mit destilliertem Wasser) übertragen. Vor Versuchsbeginn waren sie zur Entfernung des in den Zellwänden imbibierten Seewassers 2 Minuten lang in dem Versuchsmedium abgespült worden. Die Glasdosen wurden auf einer vertikal montierten Drehscheibe befestigt, die durch einen Elektromotor in langsame Rotation (etwa 5 U. p. M.) versetzt wurde. Durch diese Versuchsanordnung wurde erreicht, daß das Material während der Versuchsdauer von der relativ geringen Flüssigkeitsmenge ständig gut um- 
spült wurde. Die Wassermenge mußte möglichst geringgehalten werden, um nachher die als Folge der Turgorregulationsvorgänge zu erwartenden Änderungen der ionalen Zusammensetzung des Außenmediums analytisch gut erfassen zu können. Nach Ablauf festgelegter Versuchszeiten wurden die Glasdosen von der Drehscheibe abgenommen,

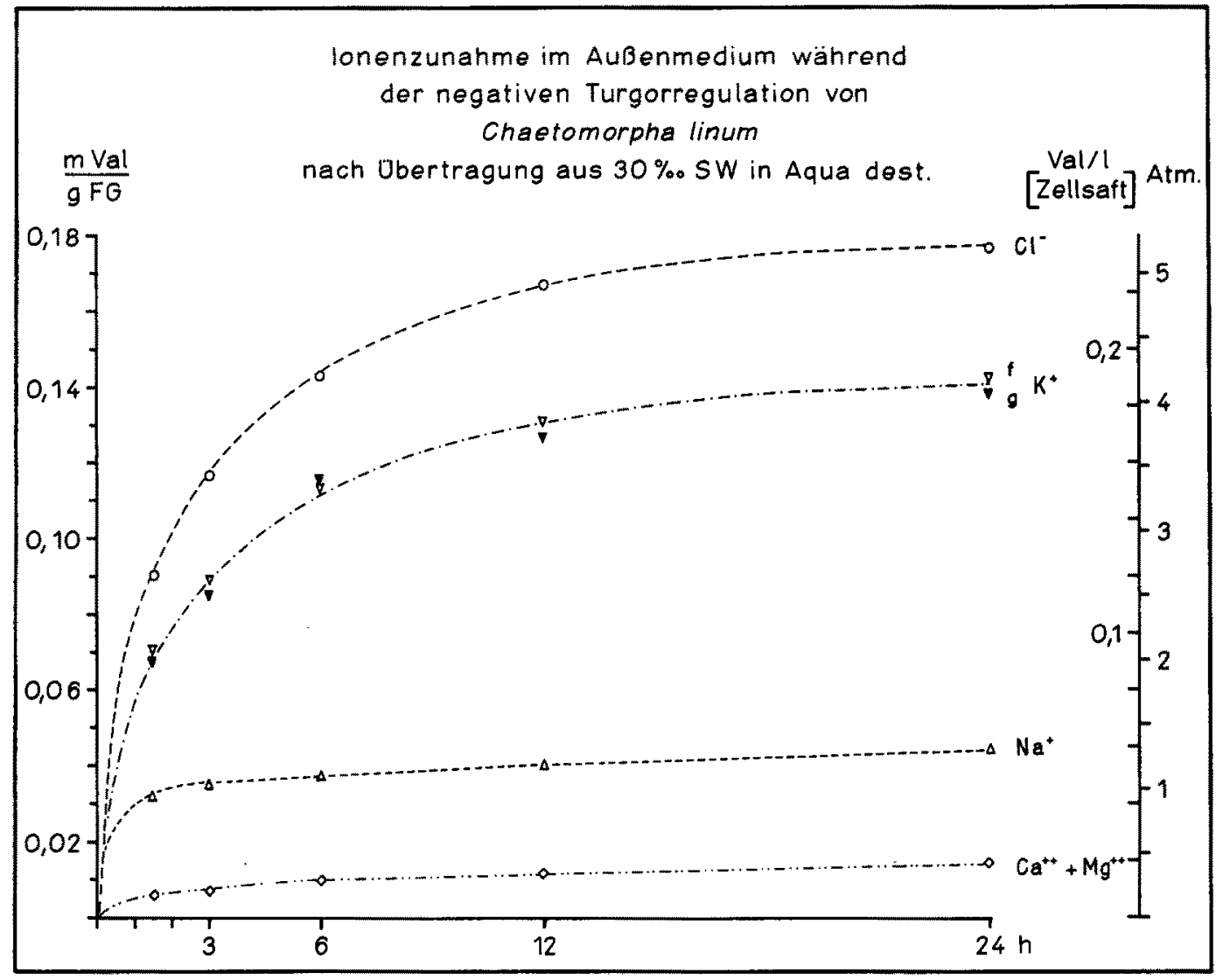

Abb. 2: Ionenzunahme in Außenmedium während der negativen Turgorregulation nach Übertragung des Versuchsmaterials aus $30 \% \mathrm{SW}$ in destilliertes Wasser. Die doppelt eingetragenen Werte für $K^{\prime}$ wurden auf verschiedene Weise gewonnen: Zunächst wurde das Kalium mit "Kalignost" (Natriumtetraphenyloborat MERCX) als Kaliumtetraphenyloborat gefällt und nach Trodknung gravimetrisch bestimmt $(\mathrm{g})$. Gemäß diesen Ergebnissen wurden die Eichlösungen für dịe Flammenphotometrie angesetzt, mit deren Hilfe der Kaliumgehalt der Versuchswasserproben nochmals ermittelt wurde $(f)$

die Materialproben zur Entfernung des in den Zellwänden imbibierten Versuchsmediums 2 Minuten lang in destilliertem Wasser abgespült und dann im Trockenschrank bei $50^{\circ} \mathrm{C}$ bis zur Gewichtskonstanz getrocknet. Die getrockneten Proben wurden schließlich mit je $200 \mathrm{ml}$ kochendem Wasser extrahiert, und danach in den Extrakten wie auch in dem Versuchswasser aus den Glasdosen die Bestimmung der wichtigsten anorganischen Ionen des Seewassers vorgenommen. Alle hier beschriebenen 
Versuche wurden bei Zimmertemperatur und konstanter schwacher Beleuchtung von etwa 100 Lux (Leuchtstofflampe) durchgeführt.

In den folgenden Diagrammen sind nur die Ergebnisse der $\mathrm{Cl}^{\prime}-, \mathrm{K}{ }^{*}-\mathrm{Na}{ }^{\circ}, \mathrm{Ca}{ }^{*}-+$ $\mathrm{Mg}$ "- und $\mathrm{Ca}^{\prime \prime}$-Analysen wiedergegeben. $\mathrm{Cl}^{\prime}$ wurde nach MoHr mit n/20 Silbernitrat und Kaliumchromat als Indikator titriert. $\mathrm{K}^{*}$ und $\mathrm{Na}^{*}$ wurden flammenphotometrisch gemessen (BECKMAN Spektralphotometer, Modell DU mit Flammenzusatz) und $\mathrm{Ca}$ “ und Mg" komplexometrisch mit ADTE (Athylendiamintetraessigsäure) bestimmt (zunächst $\mathrm{Ca}^{*}+\mathrm{Mg}^{\prime \prime}$ bei $\mathrm{pH} 10$ mit MERCK-Indikatorpuffertabletten, dann $\mathrm{Ca}^{*}$ allein bei $\mathrm{PH}_{\mathrm{H}} 13$ mit Calconcarbonsäure [MERCK] als Indikator).

Bei der Darstellung und Besprechung der Ergebnisse wurden folgende Abkürzungen verwandt: $\mathrm{mVal}=$ Milliäquivalent; $\mathrm{Val} / 1$ [Zellsaft $]=$ Konzentration der bestimmten Ionen im Zellsaft in Aquivalent pro Liter; Atm = Osmotischer Wert der bestimmten Ionen in Atmosphären (nach Umrechnung auf den Zellsaftraum); g FG = Gramm Frischgewicht; SW = Normales Seewasser; KSW = Künstliches Seewasser.

Die auf der rechten Seite der Abbildungen 2, 4, 5, 6, 7 und 9 eingezeichneten Maßstäbe gestatten die direkte Ablesung der Meßwerte in Einheiten der Zellsaftkonzentration bzw. in Atmosphären. Zur Ermittlung der Zellsaftkonzentration mußten die Analysendaten auf das Zellsaftvolumen umgerechnet werden. Letzteres wurde nach 10 Minuten langem Zentrifugieren der Algen bei 5000 U. p. M. durch Ausmessen des plasmafreien Zellumens unter dem Mikroskop bestimmt. Das Mittel von 50 Messungen diente dabei als Umrechnungsfaktor. Das Zentrifugieren wurde von den Algen gut vertragen. Nach etwa 48 Stunden hatte sich das Protoplasma samt Einschlüssen wieder nahezu gleichmäßig über die Zellen verteilt, die daraufhin ihr Wachstum ohne ersichtliche Störungen fortsetzten. Auch die Polarität der Zellen blieb unverändert.

\section{VERSUCHSERGEBNISSE UND DISKUSSION}

Abbildung 2 gibt die Ergebnisse eines Versuches wieder, bei dem das Material aus $30 \%$ Seewasser in destilliertes Wasser übertragen worden war. Man ersieht daraus, $\mathrm{da} ß$ von den Algen während der negativen Turgorregulation in der Hauptsache $\mathrm{K}^{\circ}$ und $\mathrm{Cl}^{\prime}$ zur Erniedrigung des osmotischen Potentials ihres Zellsaftes an das Außenmedium abgegeben wurden. Das Natrium als wichtigstes Kation des Seewassers rangiert dabei erst an zweiter Stelle. In Wirklichkeit diirfte die Beteiligung des Natriums an diesem Regulationsvorgang sogar noch wesentlich geringer sein, als eine oberflächliche Betrachtung des Diagramms vermuten läßt. Ein Vergleich der verschiedenen Kurven zeigt nämlich, daß die Natriumkonzentration im Gegensatz zu den anderen Ionen sehr schnell ihr Endniveau erreicht. Dieser Kurvenverlauf läßt darauf schließen, daß es zum größten Teil noch aus den Zellwänden bzw. aus dem extraplasmatischen Raum stammt. Die Ursache dafür dürtte in dem Umstand zu suchen sein, daß das Material in diesem Fall aus Mangel an Erfahrung vor Versuchsbeginn nur kurze Zeit (etwa $1 / 2$ Minute lang) in destilliertem Wasser ausgespült wurde. Diese kurze Waschzeit genügte offenbar nicht, um alles Imbibitions- $\mathrm{Na}$ aus den plasmafreien Zellräumen zu entfernen. Auch Abbildung 3, welche die Abnahme des Natriums in den getrockneten 
Materialproben wiedergibt, spricht für diese Annahme. Demnach dürfte Natrium für die Regulation des Turgors osmotisch kaum von Bedeutung sein.

In Abbildung 4 sind die Ergebnisse eines weiteren Versuches zur Ermittlung der Ionenbewegungen während der negativen Turgorregulation dargestellt. Hierbei wurde das Material aus $30 \%$ in $3 \%$ übertragen. Vor Versuchsbeginn wurde es mit Rücksicht auf die bei der ersten Versuchsserie gesammelten Erfahrungen 2 Minuten lang im

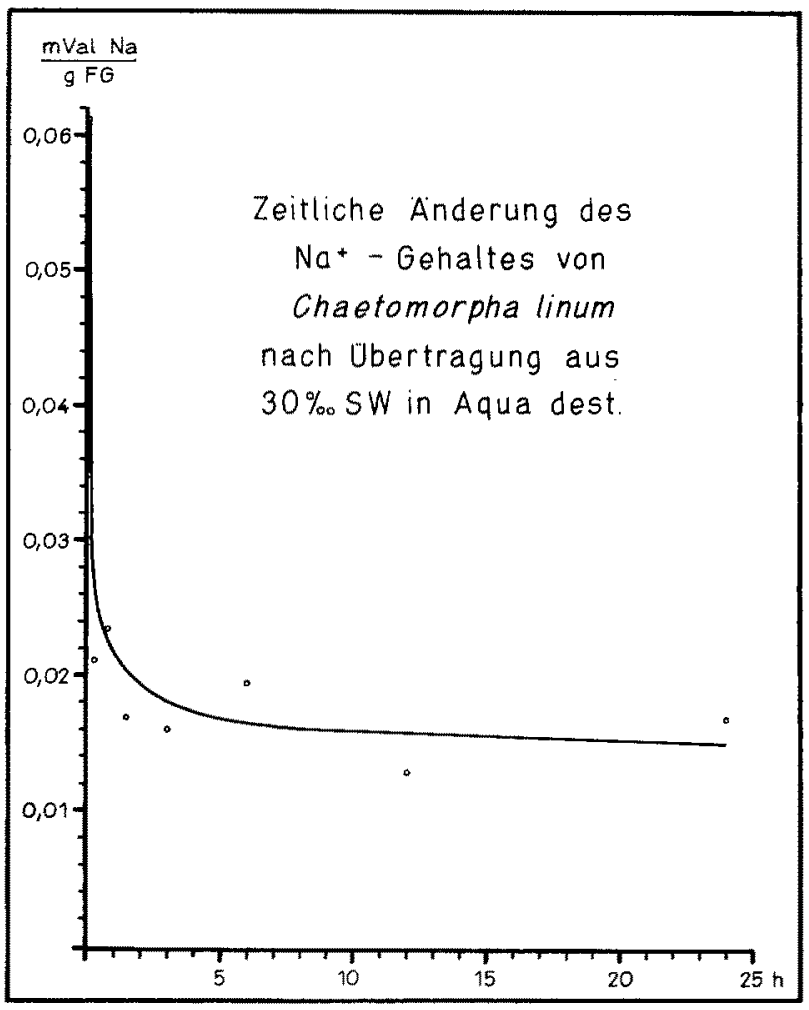

Abb. 3: Zeitliche Änderung des Natriumgehaltes von Chaetomorpha linum nach Übertragung aus $30 \% \mathrm{SW}$ in destilliertes Wasser

$3 \%$-Medium ausgewaschen. Zwar konnte die genaue Änderung der Natriumkonzentration im $A u B e n m e d i u m$ in diesem Falle nicht verfolgt werden, da sie im Verhältnis zu dessen Ausgangskonzentration zu geringfügig war (maximal etwa $2 \mathrm{mVal}$ gegenüber $41 \mathrm{mVal}$ ). Die Werte für die Na-Abnahme im Material lassen aber erkennen, daß durch die verlängerte Auswaschzeit die abgegebene Menge gegenüber dem Aquadestillata-Versuch um etwa $60 \%$ reduziert werden konnte. Auch die weitaus geringere Differenz zwischen den $\mathrm{K}^{\circ}$ - und $\mathrm{Cl}^{\prime}$-Werten zeigt, daß zusammen mit dem $\mathrm{Na}$ eine äquivalente Menge an $\mathrm{Cl}^{\prime}$ als Hauptanion des Imbibitionswassers mitentfernt wurde. Es kann zwar als sicher gelten, daß auch durch die zweiminütige Vorspülung des Materials noch nicht alles Imbibitions- $\mathrm{Na}$ und $-\mathrm{Cl}$ aus den extraplasmatischen Zellbestandteilen entfernt wurde; auf eine weitere Verlängerung der Auswaschzeiten wurde jedoch ver- 
zichtet, um dabei keine zu hohen Verluste der für die Turgorregulation wichtigen Ionen zu riskieren.

In Abbildung 4 sind außer den Analysenergebnissen der Versuchswasserproben auch noch die in den Trockensubstanzextrakten ermittelten Ionenkonzentrationen eingetragen worden. Durch diese Darstellungsweise läßt sich leicht nachprüfen, ob bei der

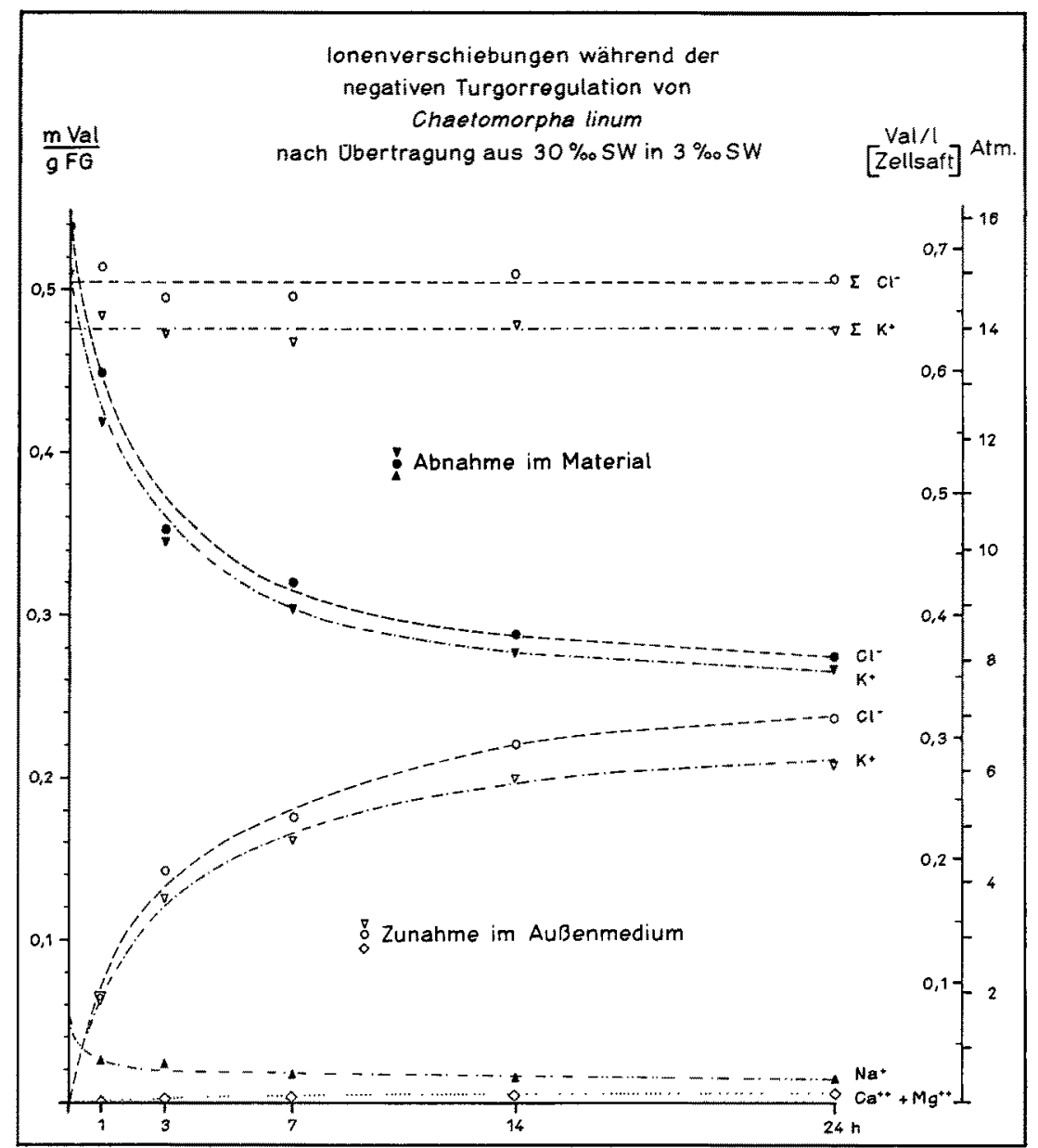

Abb. 4: Ionenverschiebungen während der negativen Turgorregulation nach Obertragung des Versuchsmaterials aus $30 \%$ SW in $3 \%$ SW

Heißwasserextraktion auch wirklich der gesamte noch in den Zellen verbliebene Rest der wasserlöslichen, das heißt also osmotisch aktiven Ionen, eluiert wurde. In diesem Falle muß nämlich die Summe der abgegebenen und der noch im Material verbliebenen Ionen für alle Versuchszeiten annähernd gleich sein. Abbildung 4 zeigt, daß diese Bedingung zumindest für die Hauptionen $\mathrm{K}^{\prime}$ und $\mathrm{Cl}^{\prime}$ im Rahmen der Fehlergrenzen erfüllt ist. 
Zur besseren Vergleichbarkeit sind in Abbildung 5 noch einmal die Analysenergebnisse dieser beiden osmotisch wichtigsten Ionen, berechnet als Zunahme im Außenmedium beziehungsweise als Abgabe durch das Material, dargestellt.

Aus den letzten beiden Diagrammen ist zu ersehen, daß das osmotische Potential des Zellsaftes in diesem Falle innerhalb von 24 Stunden um etwa 14 Atm gesenkt wurde. Demgegenüber beträgt die Differenz zwischen den osmotischen Potentialen von

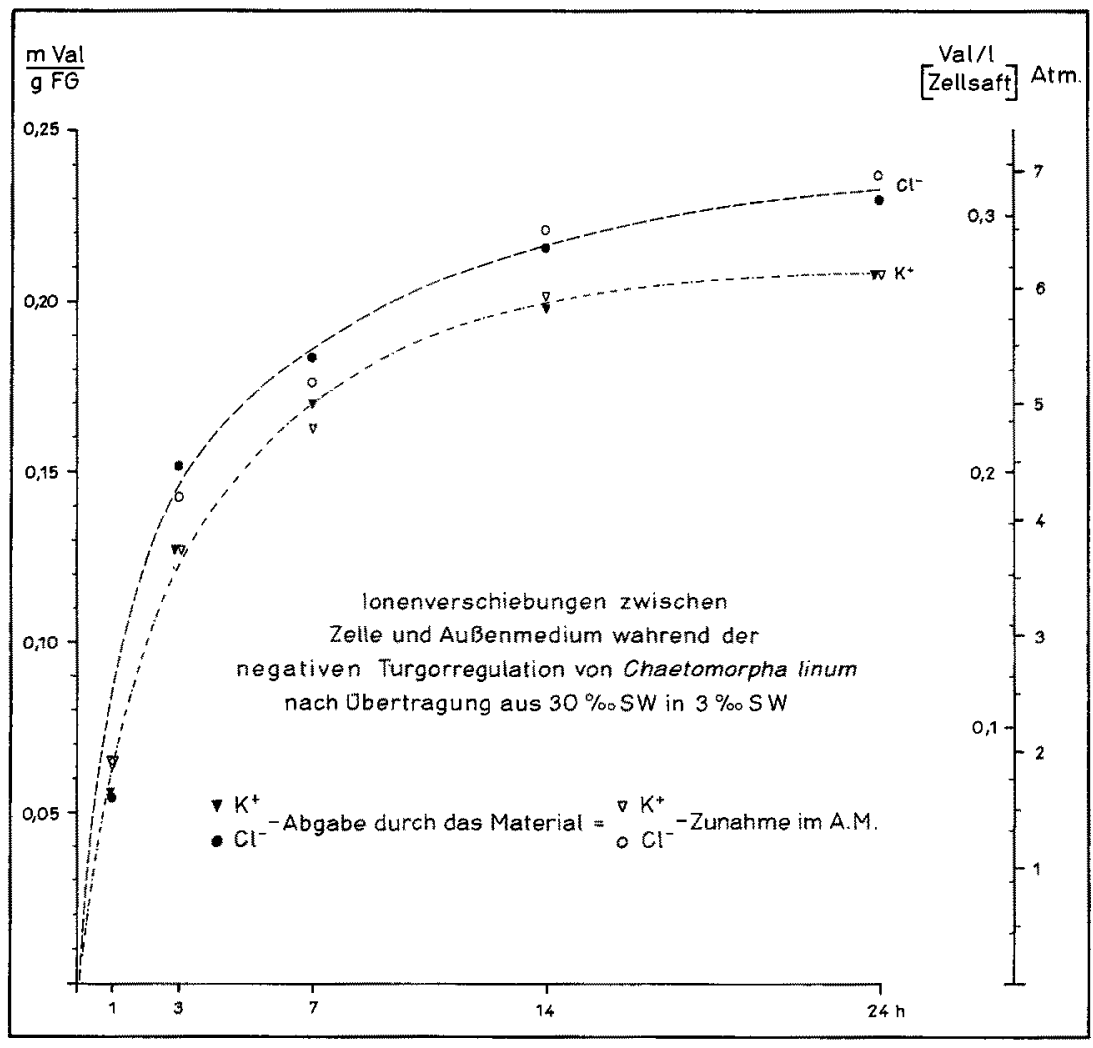

Abb. 5: Ionenverschiebungen zwischen Zellen und Außenmedium während der negativen Turgorregulation nach Obertragung des Versuchsmaterials aus $30 \%$ SW in $3 \% 0 \mathrm{SW}$

$30 \%$ und $3 \%$ rund 17,5 Atm. Die Regulationsleistung betrug also etwa $80 \%$ des experimentell erzeugten Potentialsprunges im Außenmedium. Im Hinblick auf den Verlauf der Kurven, der anzeigt, daß die Regulation des Turgors bei Versuchsende noch nicht abgeschlossen war und unter Berücksichtigung der mit mancherlei Unsicherheitsfaktoren behafteten Umrechnungsmethoden kann dieses Ergebnis als zufriedenstellend betrachtet werden.

Über die Ionenverschiebungen zwischen Zelle und Außenmedium während der positiven Turgorregulation geben die Abbildungen 6 und 7 Auskunf. Das für diese Untersuchungen verwandte Material wurde zunächst 3 Tage lang in mehrfach gewechseltem Seewasser von $3 \%$ bzw. in Regenwasser aufbewahrt. Nach erfolgter 
Anpassung wurde es in Portionen von je $5 \mathrm{~g}$ Frischgewicht in Glasdosen mit $100 \mathrm{ml}$ Seewasser von $30 \%$ mit doppeltem Kaliumgehalt übertragen. Die Erhöhung des Kaliumgehaltes war erforderlich, um eine zu starke Abnahme dieses für die Turgorregulation wichtigen Kations als Folge der zu erwartenden starken $\mathrm{K}$-Aufnahme durch das Versuchsmaterial zu vermeiden. In $100 \mathrm{ml}$ Seewasser von 30\% Salzgehalt sind nämlich nur rund $0,9 \mathrm{mVal} \mathrm{K}$ enthalten, die zusammen mit einer äquivalenten Menge $\mathrm{Cl}^{\prime}$ als Anion gerade ausreichen, um (nach Umrechnung auf das Zellsaftvolum von $5 \mathrm{~g}$ Frischmaterial) einen Potentialsprung im Außenmedium von $10 \mathrm{Atm}$ zu kompensieren. Im übrigen wurde bei diesen Versuchen methodisch in der gleichen Weise verfahren, wie bei der Untersuchung der negativen Turgorregulation.

Die Bestimmung der Abnahme des Chlorids im Außenmedium, die in 48 Stunden maximal nur etwa 1,5\% des Ausgangswertes betrug, führte zu stark streuenden Ergebnissen. Die Ursache dafür dürtte u. a. vor allem in dem Umstand zu suchen sein, daß bei der positiven Turgorregulation, bei der es zunächst zu einer vorübergehenden teilweisen oder vollständigen Aufhebung des Zellturgors kommt, weitaus stärkere Wasserbewegungen und damit Zellvolumänderungen stattinden als bei dem entgegengesetzten Regulationsvorgang. Diese unkontrollierbaren Vorgänge konnten natürlich bei der Berechnung nicht berücksichtigt werden. Man kann sich aber leicht ausrechnen, daß eine Volumänderung des Materials von nur 5\% bereits zu einem Fehler von 20 bis $30 \%$ bei der Chloridbestimmung führen muß. Erst durch Mittelung einer größeren Anzahl von Meßwerten verschiedener Materialproben (für den hier beschriebenen Versuch jeweils 8) konnten einigermaßen annehmbare Resultate erzielt werden, die den Ergebnissen der Kaliumanalysen etwa entsprachen.

Ahnlich wie bei der negativen Turgorregulation war auch in diesem Falle das Natrium an der Anderung des osmotischen Potentials des Zellsaftes nur in verhältnismäßig bescheidenem Umfange beteiligt (hier wie dort mit nur etwa $10 \%$ des Chloridwertes), vorausgesetzt, daß es überhaupt aus dem Zellsaft stammte. Die Anderung der Natriumkonzentration im Außenmedium konnte selbstverständlich wegen ihrer Geringfügigkeit (etwa $0,1 \%$ ) nicht nachgewiesen werden.

$\mathrm{Zu}$ Abbildung 6 ist noch $\mathrm{zu}$ bemerken, daß die $\mathrm{K}$ - und $\mathrm{Cl}^{\prime}$-Werte der 7 h-Proben sämtlich zu hoch ausfielen, so daß die Kurven an diesem Punkt einen deutlichen Knick aufweisen. Eine stichhaltige Erklärung für diesen merkwürdigen Umstand konnte bisher nicht gefunden werden. Es kann lediglich festgestellt werden, daß sich sämtliche 8 Proben gleichzeitig (von etwa $12.30 \mathrm{Uhr}$ bis $19.30 \mathrm{Uhr}$ ) auf der Drehscheibe befunden hatten. Die durch eine Klimaanlage geregelte Raumtemperatur betrug $20^{\circ} \pm$ $1^{\circ} \mathrm{C}$. Die Fenster des Laboratoriums waren durch eine Jalousie gegen direktes Tageslicht abgeschirmt, so daß als Lichtquelle praktisch nur eine in $1 \mathrm{~m}$ Abstand von der Versuchsapparatur aufgestellte Leuchtstofflampe von $40 \mathrm{~W}$ in Betracht kam. Der verhältnismäßig hohe Wert der 7 h-Proben für $\mathrm{K}^{*}$ und $\mathrm{Cl}^{\prime}$ kann daher nicht auf einen Temperatur- oder Lichteffekt zurückgeführt werden. Inwieweit hier durch die besondere Gunst der Umstände der Einfluß einer endogenen (etwa Tag-Nacht) Rhythmik sichtbar geworden sein mag, müssen weitere Untersuchungen zeigen.

Die 14h-Versuchswasserproben waren vor Beginn der Chloridtitration versehentlich etwa 3 Stunden lang unverschlossen stehengeblieben und dabei vorübergehend starker Sonneneinstrahlung ausgesetzt gewesen. Dabei muß es zu einer geringfügigen 


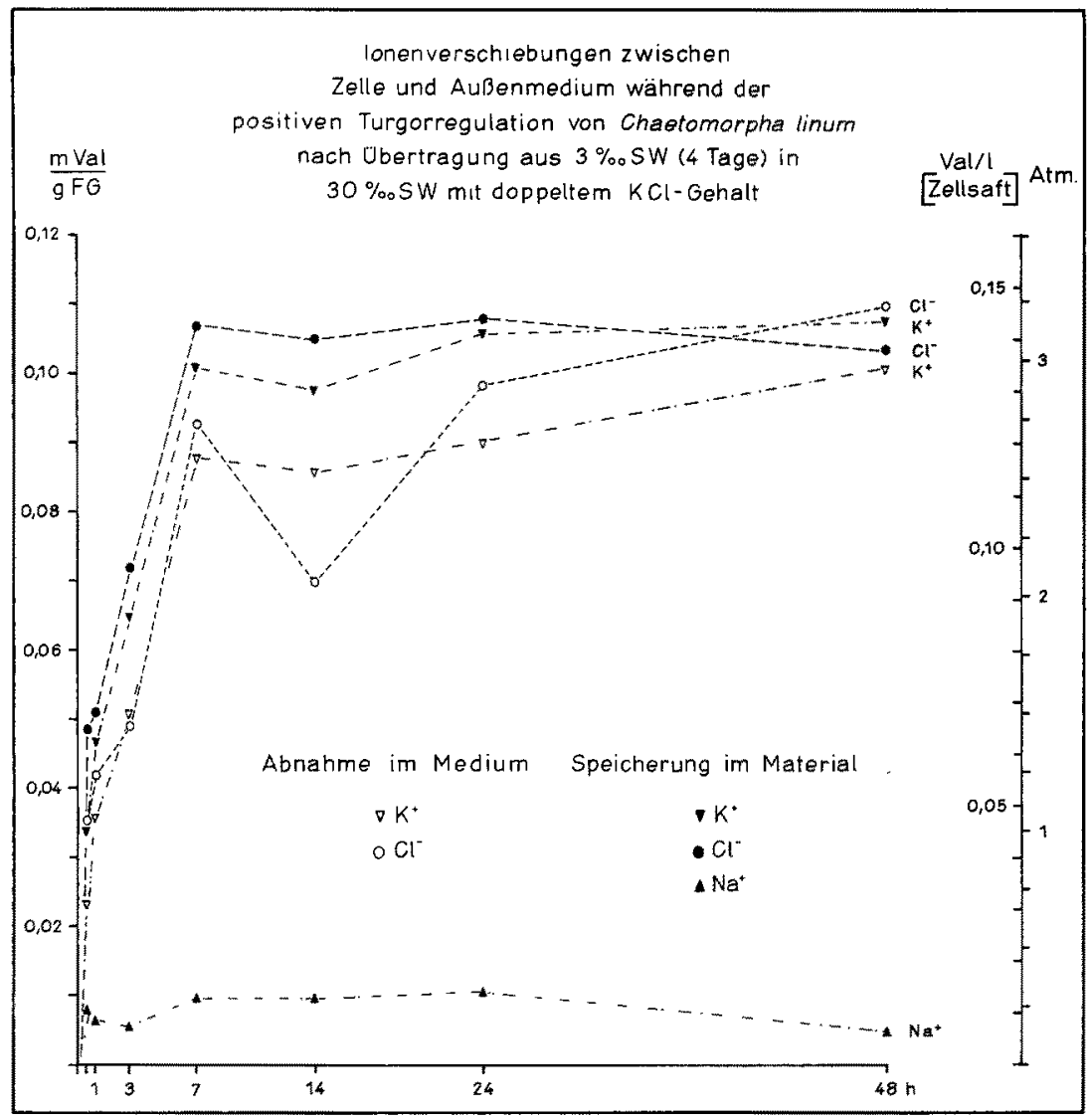

Abb. 6: Ionenverschiebungen zwischen Zellen und Außenmedium während der positiven Turgorregulation nach Übertragung des Versuchsmaterials aus $3 \%$ SW in $30 \%$ SW mit doppeltem $\mathrm{KCl}-\mathrm{Gehalt}$

Eindunstung der Proben gekommen sein. Die Abweichung des 14h-Chloridwertes von dem erwarteten Kurvenverlauf entspricht einem mittleren Verdunstungsverlust der Proben von 0,05 (!) $\mathrm{ml}$.

Der relativ große Unterschied zwischen den Kurven für die Abnahme der K - und $\mathrm{Cl}^{\prime}$-Tonen im Außenmedium einerseits und für deren Speicherung im Material zum anderen, die im Idealfalle hätten identisch sein müssen (vgl. Abb. 5), ist wohl darauf zurückzuführen, daß der von den Analysenergebnissen der Extraktproben abzuziehende Nullwert unglücklicherweise zu hoch ausfiel. Bei der Wahl des Frischgewichtes als Bezugsgröße ist jedoch immer mit derartigen unvermeidbaren Fehlern zu rechnen.

In Abbildung 7 sind zum Vergleich die Kaliumwerte eines weiteren Versuches zur positiven Turgorregulation von Chatomorpha linum wiedergegeben, die eine wesentlich bessere Übereinstimmung der Analysenergebnisse zeigen. In diesem Falle streuten jedoch die an nur je 4 Materialproben gewonnenen Chloridwerte so stark, daß auf ihre Darstellung verzichtet wurde. 
Zusammenfassend läßt sich auf Grund der bisher vorliegenden Meßergebnisse feststellen, daß audh bei der positiven Turgorregulation $\mathrm{K}^{*}$ und $\mathrm{Cl}^{\prime}$ für die Anderung des osmotischen Potentials des Zellsaftes praktisch allein entscheidend sind. Dieser Vorgang beansprucht jedoch wesentlich mehr Zeit als die Kompensation eines gleich-

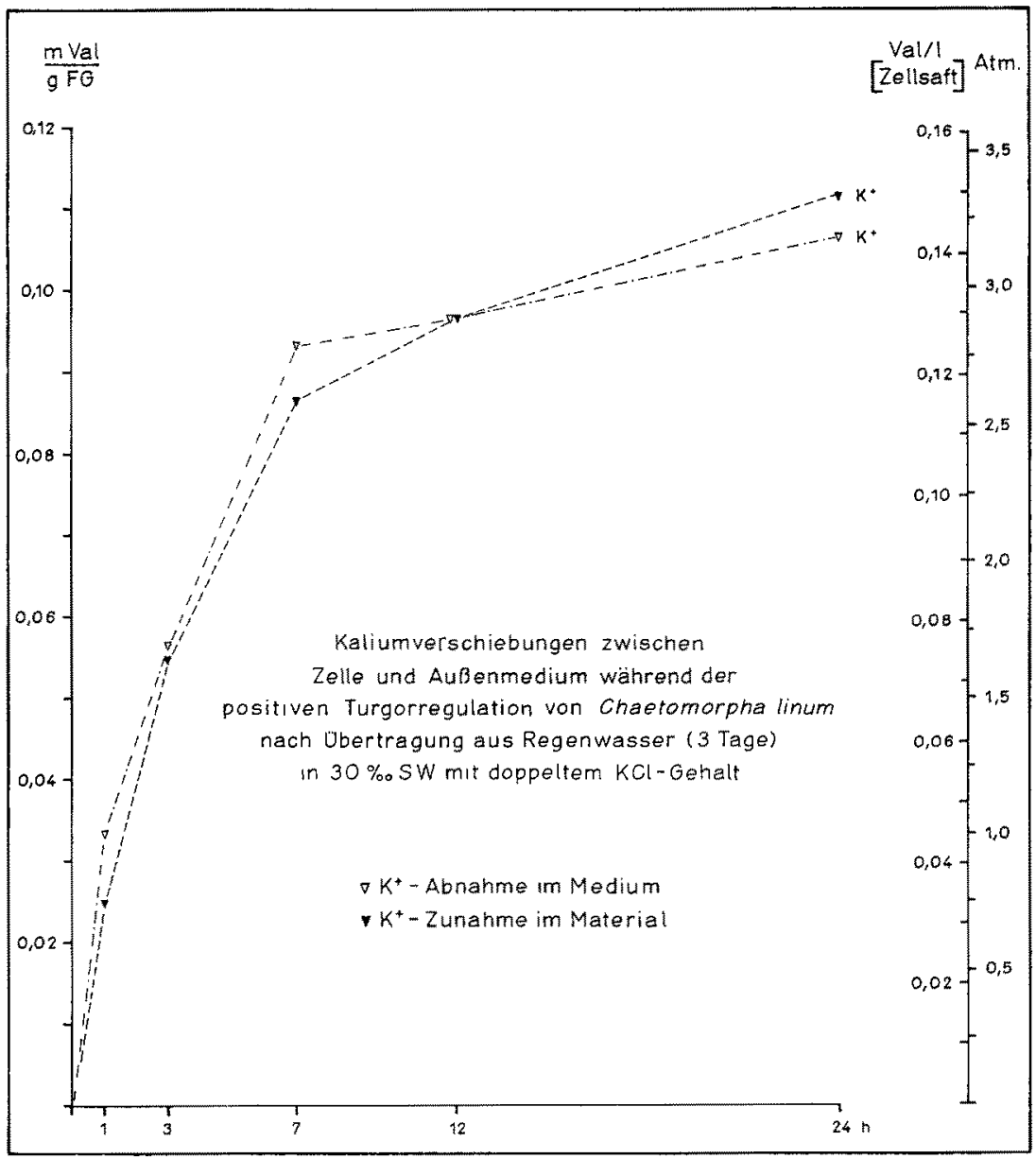

Abb. 7: Kaliumverschiebungen zwischen Zellen und Außenmedium während der positiven Turgorregulation nach Ubertragung des Versuchsmaterials aus Regenwasser in 30\% SW mit doppeltem $\mathrm{KCl}-$ Gehalt

großen Potentialsprunges während der negativen Turgorregulation. Bedenkt man jedoch, daß vom lebenden Zytoplasma im ersteren Falle unvergleichlich größere Leistungen vollbracht werden müssen, so wird dieser Sachverhalt verständlich; denn sowohl die zu speichernden Kaliumionen als auch die ständig von außen eindringenden und immer wieder aus der Zelle zu entfernenden Natriumionen müssen ja gegen ein steiles Konzentrationsgefälle bewegt werden. $\mathrm{Ob}$ und in welchem Maße die Dauer 
der positiven 'Turgorregulationsvorgänge von der Größe des experimentell erzeugten Potentialsprunges abhängig ist, müssen weitere Untersuchungen zeigen.

Es wurde bereits eingangs erwähnt, daß auch das Kalzium für den Zellturgor von Chatomorpha linum unentbehrlich sei. In den bisherigen Darstellungen trat es jedoch kaum in Erscheinung, da hier in erster Linie die osmotisch bedeutsamen Ionen berücksichtigt wurden. Seine physiologische Bedeutung konnte jedoch schon durch Atmungs-

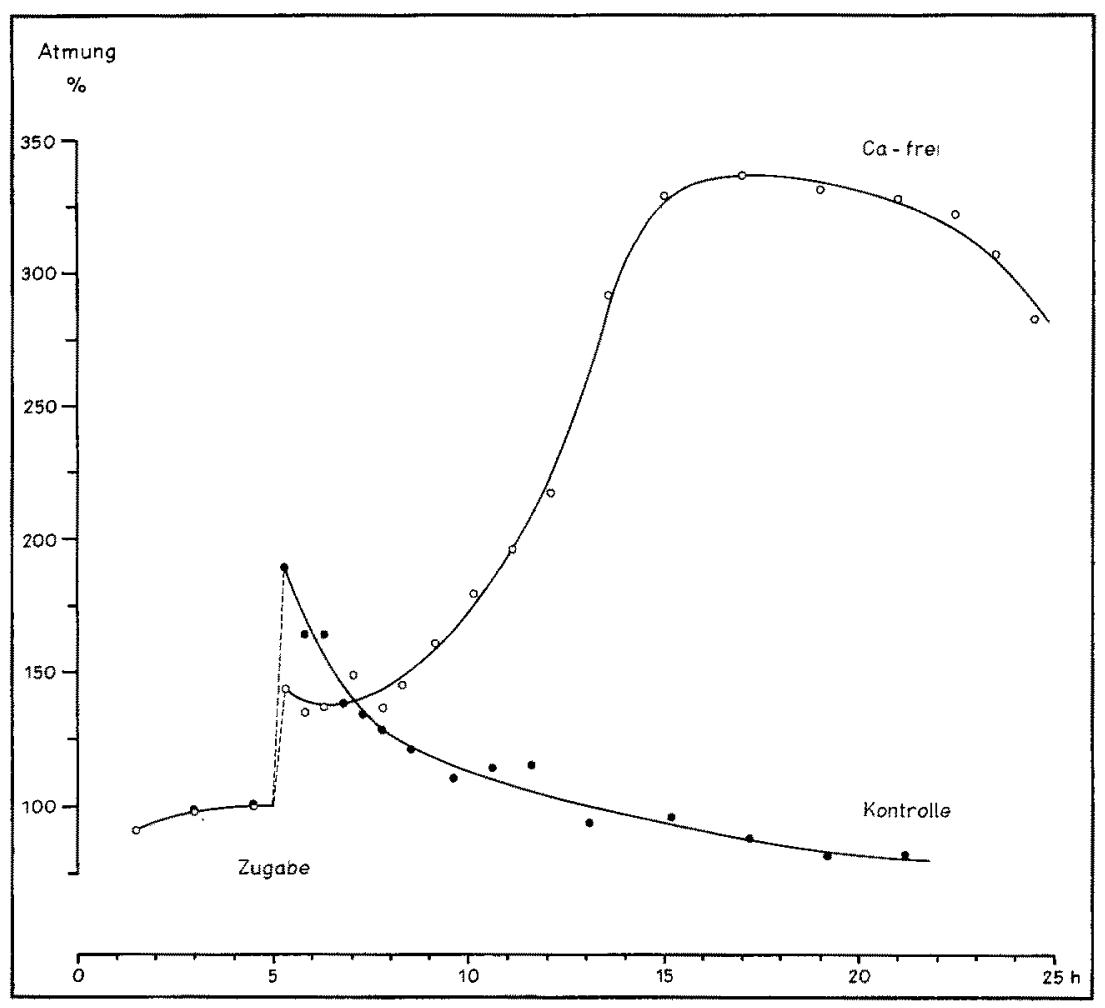

Abb. 8: Anderung der Atmungsintensität nach Obertragung des Versuchsmaterials aus $5 \%$ SW in $35 \%$ SW bzw. $35 \%$ KSW ohne Ca" (verändert nach Kesseler 1962)

messungen (Abb. 8) sowie durch mikrokryoskopische Untersuchungen (KessELER 1959, p. 59) nachgewiesen werden. Bei letzteren hatte sich gezeigt, daß in Ca-freiem Seewasser auch ohne osmotische Belastungen bereits ein Turgorschwund zu beobachten ist. Es war daher von Interesse zu untersuchen, wie es zu dieser durch Kalziummangel hervorgerufenen Turgorabnahme kommt und welche Tonenverschiebungen dabei stattfinden.

Dazu wurden je $5 \mathrm{~g}$ Frischmaterial aus 30\% SW in Glasdosen mit je $100 \mathrm{ml}$ Ca-freiem KSW vom gleichen Salzgehalt übertragen und in der üblichen Weise untersucht. Die Ergebnisse sind in Abbildung 9 dargestellt. Daraus ist zu ersehen, daß es bereits innerhalb weniger Stunden zu einer starken Permeabilitätserhöhung für $\mathrm{K}$. und $\mathrm{Cl}^{\prime}$ kommt. Ahnliches konnten Eppley \& Cykus (1960) an Porphyra perforata 
beobachten. Während diese Autoren jedoch gleichzeitig eine Zunahme des Natriumgehaltes bei ihrem Objekt fanden, blieb in unserem Versuch der Natriumspiegel des Versuchsmaterials trotz des steilen, von außen nach innen gerichteten Konzentrationsgefälles für dieses Ion nahezu konstant, wenn man von dem vorübergehenden Anstieg zu Beginn des Versuches absieht. Allerdings sind die Zellen von Porphyra perforata im Gegensatz zu denjenigen von Chaetomorpha linwm sehr plasmareich und besitzen nur sehr kleine Vakuolen. Demgegenüber beansprucht der Zellsaft von Chaetomorpha

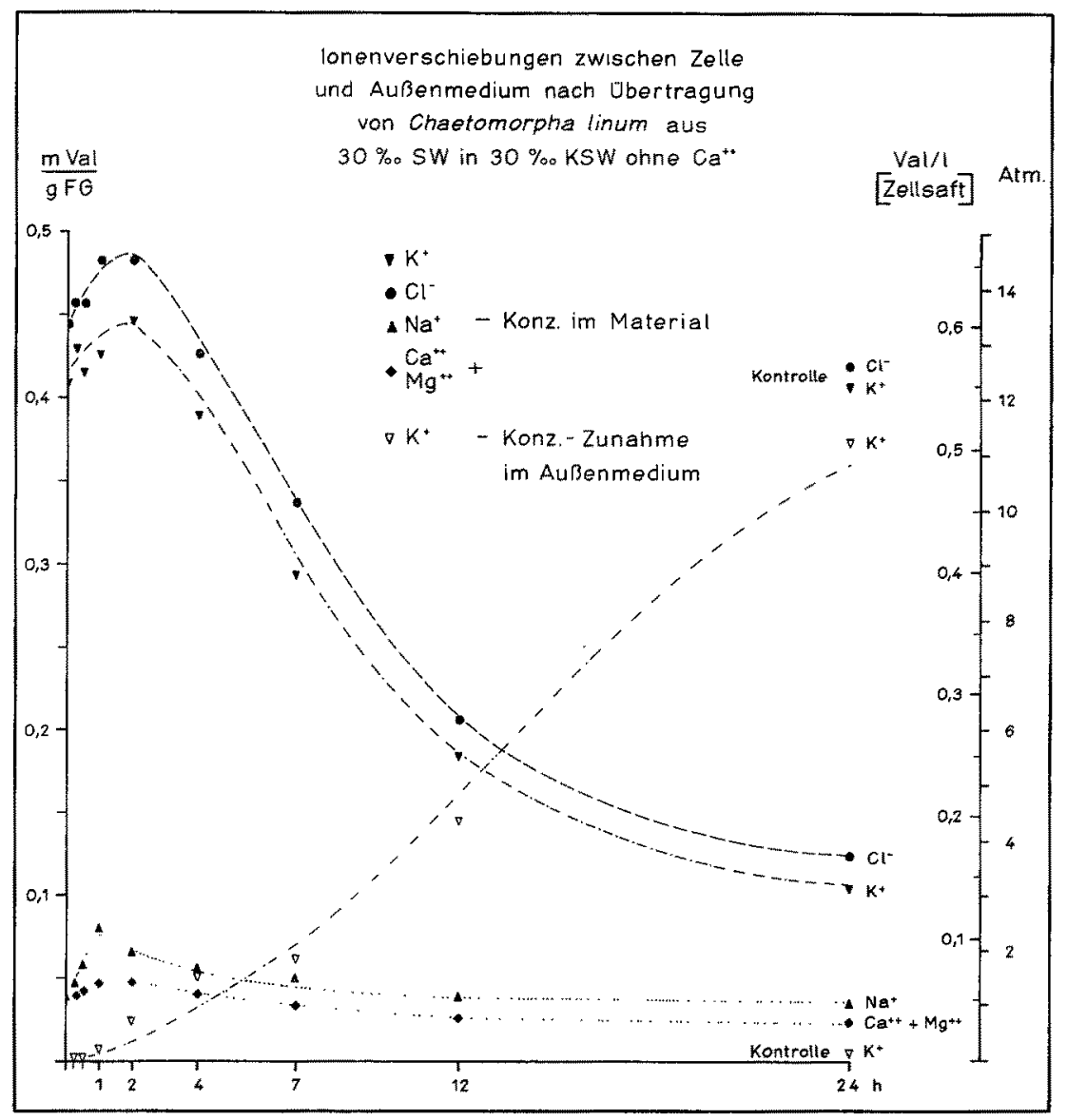

Abb. 9: Ionenverschiebungen zwischen Zellen und Außenmedium nach Übertragung des Versuchsmaterials aus $30 \%$ SW in $30 \% \mathrm{KSW}$ ohne $\mathrm{Ca} \cdot$

linum etwa $80 \%$ des Zellumens. Die unterschiedlichen Befunde scheinen dafür zu sprechen, daß das Natrium leichter in das Protoplasma einzudringen vermag als in die Vakuolen.

Völlig unerklärlich war zunächst auch die Beobachtung, daß die bei Versuchsende in den Zellen vorgefundene Restkonzentration an Kationen und Anionen nach Umrechnung auf den normalen Zellraum nur einen osmotischen Wert von 8 Atm ergab, 
während das osmotische Potential des Außenmediums 19,5 Atm betrug. Selbst bei völligem Verlust der Permeabilitätseigenschaften wäre allenfalls osmotisches Gleichgewicht zwischen Innen- und Außenmedium zu erwarten gewesen, niemals aber ein Defizit innerhalb der Zellen.

Nun war bereits früher beobachtet worden (KESSELER 1959), daß Ca-Mangel im Außenmedium eine außerordentlich starke Verquellung der Zellwände zur Folge

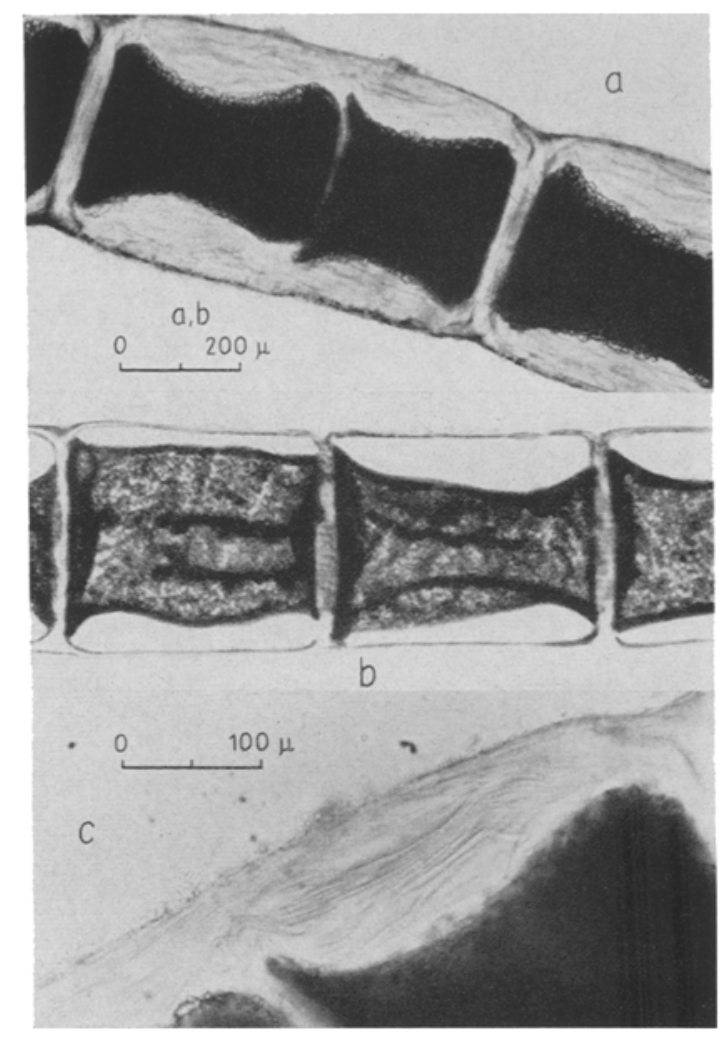

Abb. 10: Starke Verquellung der Zellwände von Chaetomorpha linum in 30\% KSW ohne $\mathrm{Ca}^{*}(\mathrm{a}, \mathrm{c})$. Mitte (b): Normale Zellwandstärke nach Plasmolyse in Harnstoff-Seewasser (nach HöFLER 1932)

hatte. Diese Beobachtung führte schließlich zur Lösung des Rätsels. Eine mikroskopische Prüfung des Materials ergab nämlich, daß die Quellung der Zellwände vor allem ins Innere der Zellen gerichtet war (Abb. 10a). Bei den innersten Membranschichten hatte sie zu einer regelrechten "Aufblätterung" in einzelne Lamellen ( $\mathrm{Abb} .10 \mathrm{c}$ ) geführt, wodurch das ursprüngliche Zellumen auf etwa $1 / 3$ seines Ausgangswertes eingeengt worden war. Abbildung 10b ermöglicht einen Vergleich mit der normalen Zellwandstärke nach Plasmolyse von Chaetomorpha-Zellen in Harnstoff-Seewasserlösungen (Hörler 1932). Auf Grund dieser starken, quellungsbedingten Volumänderungen entfielen natürlich die Voraussetzungen für eine Umrechnung der Analysenergebnisse 
auf normales Zellsaftvolum. Setzt man stattdessen den neu ermittelten Wert ein, so kommt man unter Berücksichtigung der Schwierigkeiten, die einer exakten Zellvolumbestimmung unter diesen Umständen im Wege stehen, auf einen osmotischen Wert, der etwa dem der Außenlösung entspricht. Allerdings dürfte auch durch das Auswaschen der Proben nach Ablauf der Versuchszeiten infolge der erhöhten Plasmamembranpermeabilität ein gewisser Verlust an $\mathrm{K}^{\prime}$ und $\mathrm{Cl}^{\prime}$ eingetreten sein.

In Abbildung 11 sind schließlich noch die Anderungen der Kalziumwerte des Materials während des Aufenthaltes im $\mathrm{Ca}$-freien Medium dargestellt. Man ersicht

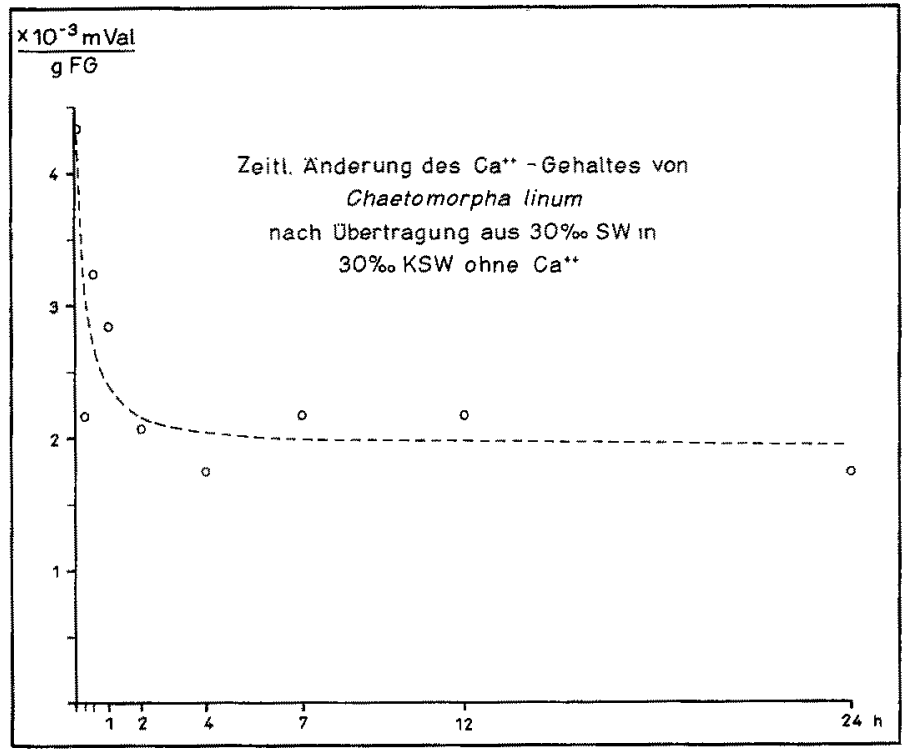

Abb. 11: Zeitliche Anderung des $\mathrm{Ca}$ "-Gehaltes von Chaetomorpha linum nach Utbertragung aus $30 \% 0 \mathrm{SW}$ in $30 \% \mathrm{KSW}$ ohne $\mathrm{Ca}^{*}$

daraus, daß die Abnahme des Kalziumgehaltes beinahe sprunghaft erfolgt. Dieser Kurvenverlauf legt den Gedanken an einen Ionenaustauschvorgang nahe.

Normalerweise dïrfte das Kalzium wegen seiner Fähigkeit zur Bildung wenig dissoziierbarer Verbindungen oder gar undissoziierbarer Komplexe mit den Carboxylgruppen von Eiweiß (NETTER 1951) und anderen carboxylreichen kolloidalen Substanzen - dazu gehören vor allem Alginsäure und verwandte Stoffe, die am Aufbau der Zellwandsubstanz von Meeresalgen in starkem Maße beteiligt sind - ziemlich fest an das Zellwandmaterial gebunden sein. Wegen seiner $Z$ weiwertigkeit kann es dabei sogar noch als Brückenbildner zwischen benachbarten Kolloidmolekülen fungieren und auf diese Weise erheblich zur Festigung solcher Substanzen beitragen. Erst in Medien, die reich an einwertigen Kationen sind, aber praktisch kein Kalzium enthalten, kann das $\mathrm{Ca}$ " durch jene verdrängt werden. In $\mathrm{Ca}$-freiem Seewasser kommt als Ersatzion in erster Linie das Natrium in Frage. Da nun aber das Natriumion, das selbst von einem starken Hydratwassermantel umgeben ist, keine undissozilerbaren Verbindungen mit dem Zellwandmaterial zu bilden vermag, muß im Ca-freien See- 
wasser nach der Hydratationstheorie von PAULI \& VALKó (1933) die Ladung und damit auch die Quellung der Zellwandkolloide stark zunehmen.

Ahnliche Vorgänge mögen auch die Ursache für die Erhöhung der Protoplasmapermeabilität für $\mathrm{K}^{*}$ und $\mathrm{Cl}^{\prime}$ sein und darüber hinaus eine Deutungsmöglichkeit für das Zustandekommen der auffälligen Kurvenmaxima in Abbildung 9 bieten. Darüber soll jedoch erst diskutiert werden, wenn sich durch weitere Versuche die Reproduzierbarkeit dieser Gipfel hat nachweisen lassen.

\section{ZUSAMMENFASSUNG}

1. Die negative Turgorregulation von Cbaetomorpha linum nach Herabsetzung des Salzgehaltes im Außenmedium beruht in der Hauptsache auf einer Erniedrigung des osmotischen Potentials des Zellsaftes durch Abgabe von $\mathrm{K}^{*}$ und $\mathrm{Cl}^{\prime}$.

2. Während der positiven Turgorregulation nach Erhöhung des Salzgehaltes im Außenmedium konnte umgekehrt eine starke Speicherung von $\mathrm{K}^{\cdot}$ und $\mathrm{Cl}^{\prime}$ beobachtet werden.

3. Das Natrium als wichtigstes Kation des Seewassers ist für beide Prozesse osmotisch kaum von Bedeutung. Die Anderung des Natriumgehaltes im Versuchsmaterial betrug in beiden Fällen nur etwa 10\% der Anderung seines Chloridwertes und nur etwa $5 \%$ der Anderung seines osmotischen Gesamtpotentials.

4. Kalziummangel im Außenmedium führte zu einer starken Abgabe von $\mathrm{KCl}$ durch die Versuchspflanzen, welche dabei einen beträchtlichen Turgorverlust erlitten.

5. Die ebenfalls durch Kalziummangel bewirkte starke Verquellung der Zellwände wird im Zusammenhang mit der sprunghaften Abnahme des Kalziumgehaltes der Versuchspflanzen auf einen Ionenaustauschvorgang zurückgeführt, bei dem das Zellwand-Kalzium durch Natrium ersetzt werden dürfte.

Meinem technischen Assistenten, Herrn J. K. Holtmann, danke ich für seine stets gewissenhafte und zuverlässige Mitarbeit bei der Durchführung der chemischen Analysen sowie für die Anfertigung der Zeichnungen und Photographien.

\section{ZITIERTE LITERATUR}

Biebl, R., 1937. OKkologische und zellphysiologische Studien an Rotalgen der englischen Süd. küste. Beib. Bot. Centralbl. Abt. A 57, 381-424.

Buchнeim, A., 1915. Der Einfluß des Außenmediums auf den Turgordruck einiger Algen. Mitt. Naturf. Ges. Bern, 70-113.

Collander, R., 1939. Permeabilitätsstudien an Charazeen. III. Die Aufnahme und Abgabe von Kationen. Protoplasma 33, 215-257.

Drevs, P., 1896. Die Regulation des osmotischen Druckes in Meeresalgen bei Schwankungen des Salzgehaltes im Außenmedium. Arch. Ver. Freunde Naturg. Mecklenb. 49, 91-135.

Epplex, R. W., 1958. Sodium exclusion and potassium retention by the red marine alga, Porphyra perforata. J. gen. Physiol. 41, 901-911.

- \& Cyrus, C. C., 1960. Cation regulation and survival of the red alga Porphyra perforata, in diluted and concentrated sea water. Biol. Bull. Woods Hole 118, 55-65. 
Höfler, K., 1931. Hypotonietod und osmotische Resistenz einiger Rotalgen. Öst. Bot. Z. 80, $51-71$.

- 1932. Plasmolyseformen bei Chaetomorpha und Cladophora. Protoplasma 16, 189-214.

KesseLER, H., 1959. Mikrokryoskopische Untersudungen zur Turgorregulation von Chaetomorpha linum. Kieler Meeresforsch. 15, 51-73.

- 1960. Morphologische und zellphysiologische Untersuchungen an Chaetomorpha linum. Helgol. Wiss. Meeresunters. 7, 114-124.

- 1962. Beziehungen zwischen Atmung und Turgorregulation von Chaetomorpha linum. Ibid. 8, 243-256.

Netrer, H., 1951. Biologische Physikochemie. Akademische Verlagsges. Athenaion, Potsdam, $325 \mathrm{pp}$.

Paul, W. \& VAlkó, E., 1933. Kolloidchemie der Eiweißkörper. Theodor Steinkopff, DresdenLeipzig.

StEINER, M. \& EsChrich, W., 1958. Die osmotische Bedeutung der Mineralstoffe. In: Handb. Pfl. Physiol. 4, 334-354.

\section{Diskussion im Anschluß an den Vortrag KesseLER}

SCHLIEper: Was können Sie aussagen über die relativen Anteile gelöster organischer Stoffe und anorganischer Ionen bei der intrazellulären osmotischen Regulation Ihrer Algen? Bei der isosmotischen intrazellulären Anpassung mariner euryhaliner Evertebraten spielen ja Aminosäuren etc. eine bedeutende Rolle.

KESSELER : Es wurden bereits früher mikrokryoskopische Untersuchungen im Zusammenhang mit der Turgorregulation von Cbaetomorpha linum durchgeführt, die immer etwas höhere osmotische Werte des Zellsaftes ergaben, so daß angenommen werden muß, daß auch organische Substanzen am Vorgang der Turgorregulation geringfügig beteiligt sind. Um welche Stoffe es sich dabei handelt, konnte jedoch im Hinblick auf die Schwierigkeiten des Nachweises organischer Spurenstoffe in salzreichen Medien noch nicht festgestellt werden. Vielleicht wird uns hier die in der Erprobung befindliche Methodik von Herrn Dr. Schasfer weiterbringen. 